\title{
A autoria única nas publicações científicas: uma revisão de literatura
}

\author{
Daniela Gralha de Caneda Queiroz \\ Doutoranda; Universidade de Brasília, Brasília, DF, Brasil; \\ daniela.caneda@ufrgs.br \\ Jayme Leiro Vilan Filho \\ Doutor; Universidade Brasília, Brasília, DF, Brasil; \\ jleiro@unb.br
}

\begin{abstract}
Resumo: O artigo disserta a respeito da autoria única nas publicações científicas. Para tanto, emprega como metodologia de pesquisa a revisão bibliográfica. Aborda, então, o assunto sob três enfoques: a autoria única propriamente dita, trazendo aspectos históricos e argumentos para sua continuidade; a consagração do autor através da autoria única, discorrendo a respeito da necessidade de estima do pesquisador, obtida através do reconhecimento científico pelos seus pares; e o estado do conhecimento atual da autoria única, apresentando os trabalhos científicos relativos ao tema, bem como os pontos de vista de pesquisadores acerca da autoria única. Finaliza com a ideia de que a autoria única nas publicações científicas não desaparecerá, principalmente em virtude do reconhecimento científico que a autoria única proporciona.
\end{abstract}

Palavras-chave: Autoria única. Publicação científica. Reconhecimento científico. Revisão de literatura.

\section{Introdução}

Em seu livro Little Science, Big Science, Price (1963) escreveu que a proporção de artigos com vários autores estava crescendo tão rápido, de forma contínua e vigorosa, que os artigos de autoria única desapareceriam. Décadas depois, Greene (2007) foi, também, alarmante ao declarar que o autor solitário desapareceu. Em sua análise na Nature, verificou que a revista mantém o número de artigos e cartas desde o ano de 1950, contudo, possui cerca de quatro vezes mais autores. Assim, continua Greene (2007), entre o final dos anos 1600 


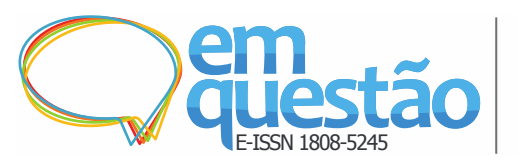

até cerca de 1920, a regra era de um único autor por artigo, porém, essa regularidade foi quebrada ainda na década de 1920, diminuída nos anos 50 e abandonada na década de 1980, quando a colaboração na pesquisa multidisciplinar passou a ser universal e essencial.

Pois bem, ainda que os artigos de autoria única não sejam mais preceito, e embora seus índices dentro da produção científica, em geral, estejam menores, eles não desapareceram. Abt (2007), em estudo a respeito das frações de artigos de autoria única em Astronomia, Física, Química e Biologia, no período de 1975 a 2005, concluiu que a função exponencial nunca chega a zero, implicando que trabalhos de autoria única continuarão a ser publicados no futuro previsível, contrariando a previsão de que eles seriam extintos. Na mesma linha de raciocínio, Vanz e Stumpf (2010), em artigo de revisão sobre os aspectos teóricos e conceituais da coautoria e da colaboração científica na literatura nacional e internacional, também descreveram que a autoria individual não desapareceu e que ela ainda existe em todas as áreas, apesar de ser proporcionalmente maior nas áreas essencialmente teóricas. Isto posto, este estudo encontra sua justificativa.

Diante disso, então, este artigo propõe-se a apresentar uma revisão de literatura a respeito da autoria única nas produções científicas. Para tanto, este artigo está dividido em três segmentos: a autoria única propriamente dita, a consagração do autor através da autoria única e o estado do conhecimento atual da autoria única ${ }^{1}$.

\section{A autoria única}

A autoria única, como prática de escrever e publicar só (MEZA; SABAJ; MATSUDA, 2017), sempre se fez presente nas produções tanto literárias quanto científicas. No que diz respeito às produções literárias, entre o fim do século XVI e o início do século XVII, havia considerável colaboração entre autores, sobretudo em peças teatrais, mas que, entretanto, acabavam sendo registradas como autoria única na edição impressa (CHARTIER, 2014). Chartier (2014, p. 


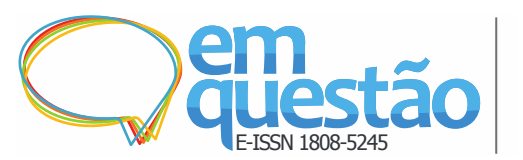

10) também descreve que durante o século XVIII surgiu um novo paradigma da escrita, baseado na individualização do escrever, na originalidade da obra literária e na consagração do autor, que buscava a "canonização" de suas obras, transformando-as em "monumentos". Este novo paradigma, prossegue Chartier (2014), rompeu com: as práticas de colaboração entre autores (principalmente nas obras teatrais nos séculos XVI e XVII), a reutilização de conteúdo, os lugares-comuns familiares e as fórmulas tradicionais, além da contínua revisão e prosseguimento de obras. Por conseguinte, os autores dessa época não estavam dispostos a dividir o "sucesso".

Tal paradigma pode ter sido decorrente do Estatuto da Rainha Anne, de 1710, na Inglaterra, em que predominavam as noções de autoria individual, originalidade estética e propriedade literária, indo contra a escrita colaborativa, a reciclagem de histórias/lugares-comuns e o direito de cópia dos papeleiros (CHARTIER, 2014). Este estatuto alterou os direitos de livreiros e impressores, que passaram a possuir o direito de cópia das obras pelo tempo de 14 anos, sendo o direito de propriedade do autor imprescritível (CHARTIER, 2014). Quiçá tal idiossincrasia tenha se refletido nas obras científicas.

Importante destacar que o conceito de paradigma aqui trazido por Chartier difere do conceito de paradigma de Kuhn, que o relaciona à natureza científica - em que as transformações de paradigmas são revoluções científicas e a transição sucessiva de um paradigma a outro, por meio de uma revolução, é o padrão usual de desenvolvimento da ciência amadurecida (KUHN, 1998). Contudo, como o próprio Kuhn (1998) coloca, o que pode ser um paradigma para um grupo, pode não o ser para outro.

Então, em relação às produções científicas, elas também eram publicadas, predominantemente, sob forma de autoria única. O cientista, aliás, pesquisava sozinho, como já comentado por Meadows (1999) e por Le Coadic (2004). Deve-se considerar que a comunicação entre os pesquisadores era mais difícil, não ensejando o trabalho em conjunto (a comunicação era realizada por cartas, que podiam levar meses até chegarem ao seu destino final). Além disso, viajar era, do mesmo modo, complexo e demorado, tanto por mar quanto por 


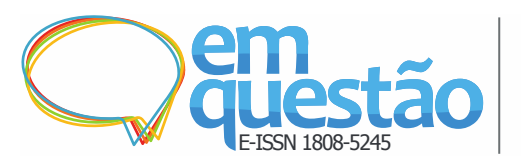

terra. Entretanto, ainda que existissem as dificuldades de comunicação e embora o sistema de transporte fosse incipiente como apontado pelos dois autores, há de se conjecturar que o pesquisador preferisse escrever sozinho porque buscava o mesmo que os escritores literários: aclamação.

Assim, como dito, do fim do século XVII até, aproximadamente, o ano de 1920, a autoria única na ciência era quase que norma. Depois, esse padrão foi rompido e a autoria única foi perdendo forças nos anos 50 (GREENE, 2007). Nos anos 80, a coautoria passou a prevalecer na ciência de um modo geral, mas não desapareceu.

À vista disso, é provável que a autoria única não tenha se extinguido na ciência em razão de:

a) preferência do autor por escrever sozinho (ELIYAN, 2014; SINGLEAUTHOR..., 2017);

b) área de interesse de pesquisa singular e/ou especializada (ELIYAN, 2014);

c) característica inerente da área de pesquisa (MEADOWS, 1999; SINGLE-AUTHOR..., 2017);

d) área de pesquisa não necessita de laboratórios nem de equipe de pessoas, viabilizando o trabalho só, de forma independente - em oposição às vantagens da colaboração, discorridos por Katz e Martin (1997);

e) intervalo de tempo menor entre a produção e a publicação efetiva do artigo, considerando-se que tanto a escrita quanto as prováveis correções sejam realizadas de modo mais paulatino quando há duas ou mais pessoas envolvidas (HARTLEY, 2005; HARTLEY; CABANAC, 2016);

f) pressão por parte de universidades, instituições de pesquisa, agentes financeiros e governos, como fator primordial para efetivação de empregos, conquista de promoções e obtenção de subsídio para pesquisa (aparentando não ser esse o caso do Brasil) (ARGENTINA, 2012; CHINCHILLA-RODRÍGUEZ; MIGUEL; MOYA-ANEGÓN，2014; 


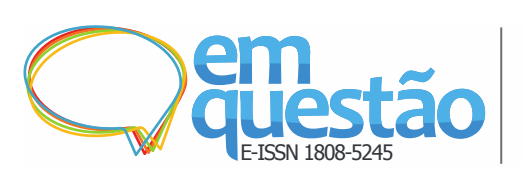

A autoria única nas publicações científicas: uma revisão de literatura

Daniela Gralha de Caneda Queiroz e Jayme Leiro Vilan Filho

ELIYAN, 2014; SINGLE-AUTHOR..., 2017);

g) demonstração de alta competência para desenvolvimento pleno de uma pesquisa (ARGENTINA, 2012; NOOR, 2013; CHUANG; HO, 2014; ELIYAN, 2014; SINGLE-AUTHOR..., 2017);

h) isolamento do autor, seja pessoal ou geográfico (SINGLE-AUTHOR..., 2017);

i) forma de libertação, após obrigatoriedade de dar coautoria para outros pesquisadores (orientadores, chefes de laboratórios, colegas mais antigos, etc.), ou depois de se livrarem do sentimento de endividamento para com outros autores (NOOR, 2013; ELIYAN, 2014);

j) glorificação só para si, considerando-se o pensamento de Merton (1957, p. 637), quando manifesta que a ciência atrai algumas pessoas egocêntricas, "famintas de fama".

Os pesquisadores têm estilos distintos de trabalho e diferentes modos de relacionar-se com os colegas. Isso para manifestar contra o fato de que há uma grande pressão para o trabalho em equipe (MEADOWS, 1999). Desse modo, quem consegue suportar a pressão pelo trabalho em colaboração e quem tem preferência por trabalhar sozinho, assim o faz. Aliás, a autoria única na comunicação científica pode ser decorrente de colaboração (LUUKKONEN; PERSSON; SIVERTSEN, 1992), sem que tenha resultado em coautoria.

Nas ciências sociais e humanas, em virtude da figura histórica, os pesquisadores estabelecidos estão menos dispostos a conceder coautoria aos subordinados - mesmo quando participaram da pesquisa (PONTILLE, 2004, apud LARIVIÈRE, 2012, p. 23) ${ }^{2}$. Além disso, Larivière (2012) expõe que, nas ciências sociais e humanas, acontecem menos interações entre os indivíduos, pois os alunos geralmente trabalham em casa, ficando envolvidos remotamente com seus professores, que não têm equipe própria e preferem realizar pesquisas sozinhos. Diante disso, pode-se cogitar que esses alunos façam suas publicações sozinhos.

Meadows (1999) analisa a profissionalização da pesquisa, julgando que 


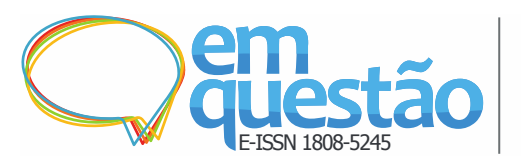

um pesquisador deve dedicar-se somente a ela. No entanto, no Brasil, o pesquisador, sobretudo o que trabalha nas universidades, atua também como docente e, em muitos casos, como administrador. Talvez tal sobrecarga de tarefas administrativas, docentes e de pesquisa possa explicar porque um autor publica sozinho, pois pode ser que ele não tenha tempo de escrever conjuntamente.

Ainda, Hartley e Cabanac (2016) apontam desvantagens para a escrita em colaboração, que aqui se entende como motivos para a autoria única: problemas surgem se os colegas não concordarem; a produção pode ser retardada se uma pessoa tiver muitos outros compromissos; os problemas surgem se o trabalho de um dos autores não for tão competente quanto o dos outros autores; pode haver dificuldades potenciais sobre quem será designado primeiro autor; os leitores/pesquisadores não sabem quem contribuiu com o quê no artigo final (embora hoje alguns periódicos forneçam essa informação, posto que existam estudos que afirmam ser isso insuficiente para a designação de valor de trabalho individual).

Apesar de a autoria única não ser mais a maior parte da produção científica em muitas áreas, ela é altamente prestigiada, pois o autor é considerado eficiente, aplicado e vitorioso, quase como um herói (ELIYAN, 2014). Segundo Chuang e Ho (2014), um trabalho de autor único exige esforços tremendos de um indivíduo, sendo frequentemente visto como o padrão-ouro e como um forte testemunho dos esforços de um cientista. Além do mais, para eles, um artigo de autor único citado é uma conquista científica notável para um pesquisador, o que o pode levá-lo à consagração, próxima seção apresentada.

\section{Consagração pela autoria única}

A autoria única pode estar intrinsecamente ligada à necessidade de estima do ser humano. Conforme a Pirâmide de Necessidades, de Abraham Harold Maslow (2001), a necessidade de estima (reconhecimento, orgulho, promoção, etc.) está, inclusive, acima da necessidade de autorrealização (trabalho desafiante, 


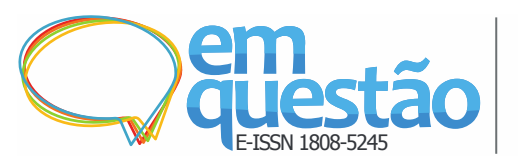

participação em decisões, crescimento pessoal etc.). Isto posto, ratifica-se o que Hochman (1994) afirmou: o pesquisador busca satisfazer-se pessoalmente, acima dos interesses da ciência. Da mesma maneira, Bourdieu (2004b) já escrevera que o prêmio do crédito científico (honorific credit) não é o dinheiro, mas sim as recompensas vindas das avaliações dos pares, da reputação, dos prêmios etc. Desse modo, o pesquisador iria contra as normas para a comunidade científica de Merton (1968). Assim, pode-se inferir que o pesquisador que publica sozinho busca atender essa necessidade de estima, de modo que só ele se consagre (notoriedade exclusiva), sem dividir atenção nem sucesso.

Merton (2013), da mesma forma, descreve que o reconhecimento é um fator motivacional, derivado de ênfases institucionais (MERTON, 1957), tendo, assim, contribuído para a ciência. Tal reconhecimento pode atingir determinado nível, transformando-se em prestígio e, depois, em reputação. E, para Merton (2013), existe uma estratificação social derivada da quantidade de prestígio. Assim, pertencer a determinado estrato, corresponde a um determinado nível de honra e estima. Em virtude disso, para os cientistas, o que importa é ter mais prestígio do que os outros colegas cientistas (MERTON, 2013).

Ziman (1988) explica que existe uma certa tendência em se atribuir grandes realizações científicas a um único indivíduo (mesmo que isso acarrete notórias injustiças). Um artigo em coautoria, por exemplo, raramente tem associado a ele o nome de todos seus coautores. Essa pode ser outra razão pela qual ainda exista autoria única nas publicações científicas. À vista disso, um pesquisador que tenha se sentido excluído da atribuição científica de determinada descoberta, pode ter decidido publicar sozinho desde então. Ziman (1988) continua, sugerindo que o prestígio decorrente do reconhecimento na ciência seria um autorreforçador para o pesquisador, facilitando o aceite no pósdoutorado em instituições de renome, a ocupação de determinados postos de trabalho, a prioridade no recebimento de recursos etc.

Ziman (1988, p. 77) explana, também, que a autoridade científica se desenvolve sobre o "Efeito Mateus", em que os ricos ficam mais ricos e os 


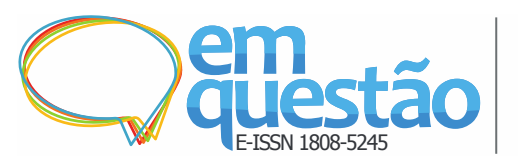

pobres ficam mais pobres, questionando se os ricos ficam mais ricos por mérito ou por sorte. Bourdieu (2004b) pensa que quanto mais conhecidos são os pesquisadores, mais produtivos são e continuam a ser. Conclui-se, portanto, que um pesquisador se torna conhecido pela qualidade científica do seu trabalho, sua produtividade (e qualidade) não tem motivação financeira (REIF, 1961). Logo, arrisca-se afirmar que a motivação não é apenas financeira ou que não é principalmente financeira.

Em conformidade com Ziman (1988), determinar o mérito de um cientista é altamente subjetivo, para tanto, faz-se uso de evidências, como a medição da produção e do impacto científico. No entanto, continua ele, nem sempre o mérito vem acompanhado de sucesso, e nem sempre os melhores cientistas estão no topo. Não obstante, seria complexo medir essas exceções. Assim, se um cientista percebe que seus trabalhos mais citados são aqueles de autoria única, acredita-se que ele, caso seja possível, optará por escrever sozinho.

Isso posto, depreende-se o capital científico, espécie particular do capital simbólico de Bourdieu (2004b), que é fundado sobre atos de conhecimento e reconhecimento. Tais atos consistem na condecoração (ou crédito) atribuída pelos pares (que são concorrentes e contribuintes ao mesmo tempo) no interior do campo científico (como por exemplo, número de menções/citações).

O campo científico de Bourdieu é tido como um campo de forças e um campo de lutas, em que os indivíduos buscam status, dominação e bens simbólicos. Ele seria o universo (mundo social) no qual estão inseridos os agentes e as instituições que produzem, reproduzem ou difundem a ciência (BOURDIEU, 2004b). Nele, os cientistas medem suas forças e travam suas lutas para serem os detentores do poder. Além disso, o campo científico (formado pelas disciplinas) é um espaço autônomo, um microcosmo dotado de leis próprias (o macrocosmo é submetido às leis sociais), variando conforme as leis da comunidade científica.

As revoluções científicas têm como efeito a transformação da hierarquia: aspectos considerados sem importância podem ser reativados por uma nova 


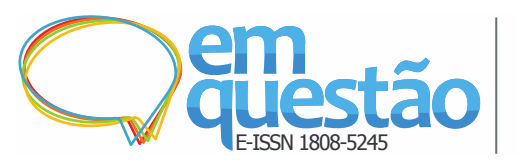

maneira de fazer ciência (subvertendo as relações de força) e, inversamente, setores inteiros da ciência podem ficar desatualizados, ultrapassados (BOURDIEU, 2004b). Em vista disso, as lutas no interior do campo são para ser ou permanecer atual. "Os dominantes consagram-se às estratégias de conservação, visando assegurar a perpetuação da ordem científica estabelecida com a qual compactuam." (BOURDIEU, 1983, p. 137).

Arrisca-se a pensar, diante disso, que um autor com força que publica sozinho, assim o faz para que essas lutas permaneçam convenientes para ele. Coelho (2017), seguindo essa tendência de pensamento, esclarece que todo conhecimento científico está perpassado por diversos interesses políticos, econômicos etc., sendo, então, a própria validade do conhecimento determinada por inúmeros interesses sociais. Coelho (2017) ainda manifesta que aqueles cientistas que possuem status (publicações em revistas bem qualificadas, citações, títulos relevantes, entre outros) estão legitimados a ditar as regras, determinando quem está "apto" ou não a participar do "jogo de forças" constituído no campo científico.

Destarte, o campo científico de Bourdieu (1983, 2004a, 2004b) possui duas formas de poder que correspondem às duas espécies de capital científico (K): o capital científico institucionalizado, da instituição, ou institucional, e o capital científico puro. O capital científico institucionalizado é caracterizado por: o poder é temporal (ou político), ou seja, o poder está ligado à ocupação de posições importantes nas instituições científicas, direção de laboratórios ou departamentos, pertencimento a comissões, comitês de avaliação etc., da mesma forma que está ligado ao poder sobre os meios de produção (contratos, créditos, postos etc.) e de reprodução (poder de nomear e de fazer as carreiras, por exemplo); suas estratégias políticas (específicas) exigem tempo (comissões, bancas de teses e de concursos, colóquios, cerimônias, reuniões etc.); não é formado pelos melhores pesquisadores; os indivíduos são eleitos ou aprovados por concursos.

Já o capital científico puro apresenta como características: poder específico; prestígio pessoal; repousa sobre o reconhecimento (por parte dos 


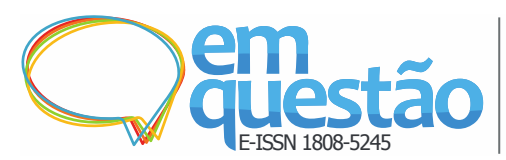

colégios invisíveis); é pouco ou mal objetivado e institucionalizado; contribuições ao progresso da ciência, invenções, descobertas (publicações)etc.; só pode ser transmitido através de longo e lento trabalho de formação (colaboração); o pesquisador formador assina com o aluno, recomenda o aluno, entre outros. No entanto, honorific credit (capital simbólico) é pessoal e intransmissível, não possuindo valor monetário (BOURDIEU, 2004b).

Por conseguinte, pode-se genericamente verificar que quanto mais as pessoas ocupam uma posição favorecida nessa estrutura, mais elas tendem a conservar ao mesmo tempo a estrutura e sua posição (BOURDIEU, 2004b). Assim, é importante refletir se um autor considerado consagrado dentro da sua área científica não escreve sozinho apenas para manter sua posição. Nesse sentido, Chang (2008) acredita que à medida que a experiência de publicação dos autores e a produtividade da pesquisa aumentam, torna-se mais provável que sua pesquisa gere conhecimento de maior valor. Bourdieu (2004b, p. 31) manifesta que "Os eruditos são interessados, têm vontade de chegar primeiro, de serem os melhores, de brilhar." (Efeito Mateus novamente).

Bourdieu (1983) entende que os investimentos dos pesquisadores - tanto na sua relevância (tempo de dedicação à pesquisa) quanto na sua natureza (grau de risco assumido) - dependem da importância do seu capital e potencial de reconhecimento e da sua posição e potencial no campo. Dessa maneira, as ambições científicas são mais altas quando o capital de reconhecimento é elevado; o título determina a carreira científica: escolha dos assuntos, grau de produtividade etc. Pressupõe-se, então, que o pesquisador que publica sozinho é detentor de capital científico elevado, não desejando se arriscar a perdê-lo; por isso, trabalha meticulosamente na escolha dos assuntos pesquisados e na quantidade produzida. Bourdieu (1983, p. 150) afirma que produtividade e competição estão diretamente ligadas, como se fossem um "mercado livre".

A passagem do capital científico puro para o capital científico institucionalizado é mais difícil. Já a passagem do capital científico institucionalizado para o capital científico puro é mais rápida e fácil, porque envolve mais poder, recebido de influências externas. Presume-se que quaisquer 


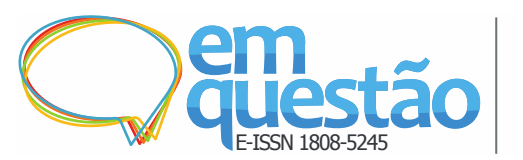

um dos tipos de capital científico seja almejado pelos cientistas e que eles são mais facilmente alcançados quando um cientista se destaca sozinho do que em grupo.

Nesse sentido, Bourdieu (1983) considera que o reconhecimento, marcado e garantido socialmente por sinais de consagração que os pares concorrentes concedem, é resultado do valor distintivo de seus produtos e da sua originalidade (no sentido da teoria da informação) reconhecidos por sua contribuição à ciência, como descreve também Merton (1957). Desse modo, Bourdieu (1983) demonstra que o capital de autoridade advindo de uma descoberta é monopolizado pelo primeiro a fazê-la ou por aquele que a torna conhecida e reconhecida. Assim, de acordo com Bourdieu (1983), se vários nomes estão ligados à primeira descoberta, o prestígio atribuído a cada um deles diminui na proporção inversa, ou seja, as assinaturas múltiplas reduzem o valor distintivo atribuído a cada um dos signatários. Para Bourdieu (1983), então, o conceito de visibility traduz o valor diferencial/distintivo do capital social, em que:

[...] acumular capital é fazer um 'nome', um nome próprio, um nome conhecido e reconhecido, marca que distingue imediatamente seu portador, arrancando-o como forma visível do fundo indiferenciado, despercebido, obscuro, no qual se perde o homem comum (BOURDIEU, 1983, p. 132).

Da mesma forma, para Reif (1961), existe uma grande importância do prestígio para o cientista, pois ele executa seu trabalho em ambiente onde é bastante dependente da boa opinião dos pares e onde sua reputação se traduz em benefícios para ele. Desse jeito, o reconhecimento pessoal possui ainda mais importância para o cientista do que para outras pessoas, fazendo com que ele se esforce para atingir prestígio máximo (REIF, 1961). Ele acredita que a necessidade de reconhecimento pelo pesquisador vem do fato de que o sucesso não é quantificável, sendo atingido quando do reconhecimento pelos pares.

Importante destacar que o reconhecimento atribuído pelos pares também é afetado pela consciência da posição ocupada pelos pesquisadores nas 


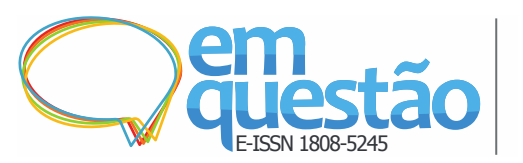

hierarquias sociais (capital simbólico) (BOURDIEU, 2004b). Em outras palavras, um pesquisador que pertença a uma instituição renomada, por exemplo, tende a receber mais crédito pelos pares. Neste caso, entram sinais de reconhecimento e consagração, tais como o prêmio Nobel, medalhas, traduções para línguas estrangeiras etc. Na mesma linha de pensamento, Reif (1961) informa que existe relação direta entre prestígio do cientista e prestígio da instituição, além disso, um cientista prestigiado atrai melhores alunos e bolsas.

Beaver e Rosen (1978) e Katz e Martin (1997) elencam em seus estudos o reconhecimento e a visibilidade como resultantes da colaboração (coautoria). No entanto, o que foi visto é que tanto o reconhecimento quanto a visibilidade podem advir da autoria única. Beaver e Rosen (1978) também já expressavam que a autoria única podia proporcionar visibilidade e reconhecimento.

Além de tudo, para Bourdieu (2004b), os pesquisadores ou as pesquisas dominantes definem, em determinado tempo, o que importa para os pesquisadores, ou seja, no que eles têm de concentrar seus esforços, em qual periódico publicar etc. Pode ser que o autor que escreve sozinho vá na contramão disso, ou seja, luta contra as forças do campo. Ainda segundo Bourdieu (2004a, p. 28), os indivíduos não são passivos, eles não estão simplesmente à mercê das forças do campo científico, eles têm disposições adquiridas (habitus), isto é, "[...] maneiras de ser permanentes, duráveis que podem, em particular, levá-los a resistir a opor-se às forças do campo.". Assim, pode ser que o autor que publica sozinho possua habitus que não o predispõe a escrever coletivamente.

Por outro lado, Canchumani e Leta (2017) exprimem que as frequentes avaliações das agências de fomento no Brasil podem estar incentivando os pesquisadores a publicarem em coautoria como forma de aumentar os seus números de artigos de periódicos, pois esse é um critério de bastante peso nas avaliações. Bourdieu (2004b), da mesma forma, coloca que houve uma inflação da coautoria, por motivos econômicos e por pressão do ambiente competitivo e empresarial.

Assim sendo, há de se pensar se o pesquisador que ainda publica sozinho 


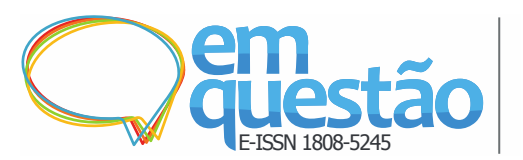

não está alheio a essas avaliações. Tal ponto vai ao encontro do que Bourdieu (2004b) pondera, de que a vida científica é dura e de que os pesquisadores sofrem muito. À vista disso, pode-se cogitar que a colaboração seja uma forma de atenuar esse sofrimento; e pode-se presumir que aquele que escreve sozinho é mais tolerante e audaz. Ademais, Meadows (1999) aponta que há mais motivos pessoais para a não colaboração cientifica do que justificativas para não a realizar por uma desculpa calcada, por exemplo, na distância geográfica.

Chinchilla-Rodríguez, Miguel e Moya-Anegón (2014), todavia, comentam que, na Argentina, a colaboração é penalizada até certo ponto, sendo recompensada a produção por um único autor. No documento Criterios de evaluación de la producción científica de las humanidades y ciencias sociales, da Comisión Interinstitucional de elaboración de criterios de evaluación para las humanidades y ciencias sociales (CIECEHCS), afirma-se, por exemplo, que, nos sistemas de avaliação para a promoção acadêmico-universitária em Humanidades e Ciências Sociais na Europa Ocidental, nos Estados Unidos e no Canadá, é exigida a publicação de um livro de autoria única como instância de demonstração do nível de maturação intelectual progressiva do candidato (ARGENTINA, 2012), como forma de justificar a valorização da autoria única Argentina.

Dessa maneira, os conhecimentos aqui apresentados vão ao encontro dos pilares do paradigma da escrita individual na produção literária, mostrando que a "propriedade literária" (CHARTIER, 2014, p. 10) de três séculos atrás ainda se faz presente, mas na produção científica. Alguns trabalhos científicos que serão apresentados a seguir, ainda que poucos, procuram mostrar isso.

\section{Estado do conhecimento}

As pesquisas acadêmicas e textos de fóruns de discussão julgados mais significativos são apresentados em seguida, proporcionando uma perspectiva sobre a autoria única na ciência. Assim, Meza, Sabaj e Matsuda (2017), em 


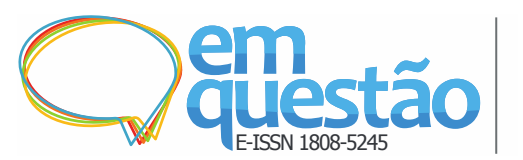

artigo cujo objetivo era o de analisar a autoria única da base de dados SciELO Chile, entre os anos de 2010 e 2014, encontraram 9541 registros em língua espanhola, correspondendo à autoria única 29\% (2741 artigos) do total publicado (aproximadamente $1 / 3$ da produção), sendo mais frequente em Ciências Humanas $(55,61 \%)$ e Sociais $(74,89 \%)$. Nas Ciências Sociais, 665 (76,44\%) autores contribuíram com apenas um artigo; 205 autores (23,56\%), com mais de um artigo. Os autores únicos tendiam a ser ocasionais, ou seja, a escrever sozinhos e apenas uma vez. A maior parte desses pesquisadores $(89,26 \%)$ estava nas universidades e em instituições privadas (53,49\%), enquanto 39,75\% estavam em instituições estatais. Os autores concluíram que a autoria única, enquanto indicador, pode ser útil para os responsáveis pelas políticas públicas científicas para gerar diferentes estratégias de financiamento, dependendo das práticas autorais de cada área.

Hartley e Cabanac (2016), em pesquisa a respeito de blogs científicos, examinaram 104 publicações no blog LSE Impact of the Social Sciences, a fim de verificar se haveria variações no estilo entre publicações de autoria única e coautoria. Os posts escritos em pares foram ligeiramente menos legíveis do que os posts de autoria única (considerados mais fáceis de ler), desafiando a visão atual sobre as vantagens de escrever em pares, segundo os autores.

Chuang e Ho (2014) estudaram as características de 1760 artigos de autoria única, a partir da coleção Science Citation Index Expanded, da Web of Science, concluindo, entre outras coisas, que tais artigos possuíam picos repetidos de citação, além de terem a palavra "teoria" como mais frequente nos títulos. Eles encontraram também uma maior porcentagem de artigos de revisão com autoria única, correspondendo a 33\% dos artigos altamente citados no Science Citation Index Expanded (SCI-EXPANDED). Além disso, eles conseguiram verificar que 72 ganhadores do Prêmio Nobel publicaram 124 artigos de um único autor.

Seguindo essa linha de investigação a respeito dos prêmios Nobel, por exemplo, Roger D. Kornberg (NOBEL MEDIA AB, [2006a]), pesquisador da Stanford University, nos Estados Unidos, que recebeu prêmio Nobel de Química 


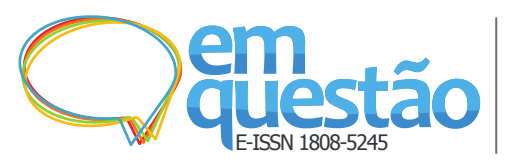

em 2006, publicou artigo sozinho referente à pesquisa vencedora do prêmio no ano de 2007, sendo seu terceiro artigo mais citado na Web of Science. Da mesma forma, Gerhard Ertl (NOBEL MEDIA AB, [2007]), pesquisador da FritzHaber-Institut der Max-Planck-Gesellschaft, na Alemanha, que recebeu prêmio Nobel de Química em 2007, tem como artigo mais citado pela Web of Science o de autoria única referente à pesquisa ganhadora do prêmio, publicado no ano de 2008. Angus Deaton (NOBEL MEDIA AB, [2015]), pesquisador da Princeton University, nos Estados Unidos, ganhador do Nobel de Economia em 2015, possui 44 registros na Web of Science, dos quais 21 são de autoria única. Entre suas dez publicações com maior número de citações, quatro são de autoria única. Edmund S. Phelps (NOBEL MEDIA AB, [2006b]), pesquisador da Columbia University, nos Estados Unidos, ganhador do prêmio Nobel de Economia em 2006, tem 13 publicações na Web of Science, sendo 9 de autoria única, das quais 3 são as mais citadas. Paul Krugman (NOBEL MEDIA AB, [2008]), pesquisador da Princeton University, nos Estados Unidos, vencedor do Nobel de Economia no ano de 2008, possui 54 publicações pela Web of Science, sendo que 35 são em autoria única. Entre suas dez publicações mais citadas, sete são de autoria única. Tais exemplos trazem a ideia de que autores mais consagrados tendem a publicar sozinhos, talvez para reforçar sua autoridade científica.

King (2013), em investigação a respeito da presença da autoria única em 21 áreas de pesquisa, entre 1981 e 2012, na base de dados Web of Science, constatou que o percentual de autoria única nas Ciências Sociais é o mais elevado, correspondendo a $40 \%$ dos artigos. O autor, ao fazer análise de citação desses artigos, averiguou que, apesar da autoria única estar em declínio, as pesquisas publicadas sob essa forma possuem peso substancial dentro da comunidade científica, pois são bastante citadas. Ao que tudo indica, os artigos de autoria única recebem significativa citação por serem trabalhos de cunho mais teórico.

Chang (2008) identificou os fatores críticos que impulsionam o valor do conhecimento criado por cientistas individuais e grupos de pesquisa. Os 


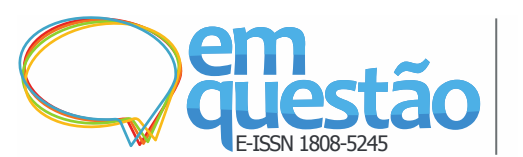

resultados sugeriram que um único autor tenderá a gerar conhecimento mais valioso; à medida que o número de autores aumenta, os resultados de suas pesquisas tendem a ser menos valiosos. Em vista disso, muitos autores não aumentam a probabilidade de produzir conhecimento extremamente valioso; quando o objetivo é criar conhecimento valioso, é melhor encontrar um indivíduo excelente.

Hart (2007), baseado em indicações de que artigos em coautoria são de qualidade superior aos artigos escritos por um autor único, realizou estudo que evidenciou isso na literatura acadêmica de Biblioteconomia. Para tanto, utilizou a contagem de citações dos periódicos Journal of Academic Librarianship (JAL) e College and Research Libraries (C\&RL), por um período de dez anos após a publicação dos artigos que foram publicados entre os anos de 1986 e 1993. Nos 542 artigos analisados e nas suas 2590 citações, nenhuma evidência estatística de significância foi encontrada para apoiar a superioridade dos artigos em coautoria. Assim, para Hart (2007, p. 195): "Os benefícios da colaboração para a produção de um manuscrito não devem ser interpretados como uma diferença de qualidade que diz respeito à publicação de artigos."

Farber (2005) fez um estudo a respeito da autoria única em diferentes disciplinas nas universidades israelenses. Concluiu que a autoria única é tendência em pesquisas de cunho teórico. Hartley (2005), em estudo sobre o tempo de submissão e o de publicação em três periódicos da área de Psicologia, encontrou que os trabalhos submetidos por autores únicos, os quais continham partes que já haviam sido apresentadas anteriormente em conferências, foram arbitrados significativamente mais rápido do que os trabalhos submetidos em coautoria. Por conseguinte, o autor conclui que não existe vantagem para a coautoria no que diz respeito à velocidade de arbitragem.

No site da ResearchGate ${ }^{3}$, rede social voltada a profissionais e pesquisadores da área de ciência, a qual permite interação e colaboração entre colegas de trabalho e áreas de estudo, em nível mundial, há dois fóruns sobre autoria única. Nestes fóruns foi perguntado aos membros: “Qual é a sua opinião sobre os documentos de um único autor?" e "Por que é cada vez mais raro ver 


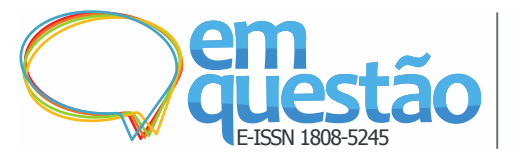

documentos de periódicos de autoria única?". Além destes, no Chronicle Forums, do jornal The Chronicle of Higher Education, de Washington, foi lançada a questão: Artigos de autoria única: um sinal bom ou ruim? E as respostas mais significativas foram:

Eu vi muitos autores se sentirem obrigados a incluir os nomes de estatísticos e líderes de organização que apenas fornecem permissão para conduzir a pesquisa em uma instalação particular. Estranho, mas a maioria das pessoas incluídas em um artigo não são realmente colaboradores no sentido mais verdadeiro. Eles apenas 'ajudam' o pesquisador com suas pesquisas. Seus nomes deveriam estar na seção de 'agradecimento'. (NOOR, 2013, on-line, tradução nossa).

Mas na minha opinião, a maior parte da autoria em um artigo pode ser drasticamente reduzida se tendermos a não nos sentir 'endividados' com os outros. (NOOR, 2013, on-line, tradução nossa).

Todos nós conhecemos colegas que estão apenas acumulando grandes currículos, acrescentando seu nome ao trabalho dos alunos e sentindo que, por serem responsáveis pelo laboratório, fazem parte de toda a pesquisa realizada lá. Isso é tão chato! (NOOR, 2013, online, tradução nossa).

Declarações de contribuições podem apresentar problemas quando algum pesquisador júnior se sentir pressionado a incluir um colega sênior que não é exatamente uma representação verdadeira da sua contribuição. (NOOR, 2013, on-line, tradução nossa).

Então, basicamente, o problema com a autoria falsa parece insuperável, infelizmente. Se você reclamar oficialmente... Sua carreira está terminada. Triste mas verdadeiro. (NOOR, 2013, online, tradução nossa).

Em alguns casos, os nomes são adicionados como coautor apenas por obrigação. Eu conheço um professor que insiste em adicionar o nome de sua filha como autor. (ELIYAN, 2014, on-line, tradução nossa).

As agências de financiamento desempenham um papel importante. Está ficando cada vez mais difícil conseguir fundos para uma nova ideia quando você é o único autor na proposta. Os árbitros pensam que 'naturalmente' ninguém concorda com você sobre a ideia que você está apresentando. Além disso, eles têm fundos limitados e querem distribuí-lo entre o maior número possível de pesquisadores. (ELIYAN, 2014, on-line, tradução nossa). 
Eu acho que, infelizmente, a razão muitas vezes não é de pesquisa, mas de finanças. Os pesquisadores relatam por suas publicações: quanto mais publicações, melhor. (ELIYAN, 2014, on-line, tradução nossa).

Eu acho que se não fosse por essas pressões externas, muitos acadêmicos levariam seu tempo e publicariam artigos individuais de alta qualidade. Talvez um artigo a cada dois anos. Basicamente, a duração de um projeto de pesquisa típico. (ELIYAN, 2014, on-line, tradução nossa).

Estas declarações demonstram que, por vezes, a coautoria existe não como resultado de colaboração científica, mas de coação. Então, fica a dúvida se os trabalhos em coautoria realmente foram executados por mais de um autor. Assim, um pesquisador que fora assediado para dar coautoria pode preferir a escrita solitária. Ademais, parece haver uma imposição financeira pela coautoria, além da imposição pela própria produção científica em si. Outras respostas obtidas nos mesmos fóruns foram: “Alguns países já começaram a avaliar os professores em seus trabalhos de autor único." (NOOR, 2013, on-line, tradução nossa); "Algumas Universidades diferenciam entre autoria única e publicação em coautoria, colocando valor diferente para cada um." (NOOR, 2013, on-line, tradução nossa); e "As agências de financiamento ainda acham que essa (autoria única) é uma conquista maior do que um trabalho de coautoria." (ELIYAN, 2014, on-line, tradução nossa). Somam-se a estas, outras respostas:

A ciência precisa de heróis, que vão contra o fluxo, as probabilidades. Aqueles que buscam os tabus. A melhor ciência vem da melhor busca, e a liberdade é o caminho. Em tempos de politicamente correto, somos metade de nós mesmos. Precisamos desesperadamente de heróis que assumam o risco de estarem errados, mas acrescentem algo diferente. (NOOR, 2013, on-line, tradução nossa).

O que me preocupa nesse contexto, entretanto, é o fato de que, em vários processos de avaliação, parece que as publicações de um único autor ainda são consideradas meritórias, enquanto os trabalhos com vários autores ganham menos peso. (ELIYAN, 2014, on-line, tradução nossa). 


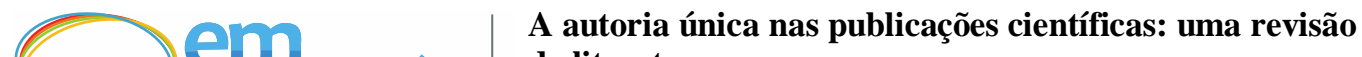 de literatura \\ Daniela Gralha de Caneda Queiroz e Jayme Leiro Vilan Filho}

No meu campo das ciências sociais, os trabalhos de autoria única são a moeda. Eles mostram que você tem ideias originais que você pode ver a fruição. (SINGLE-AUTHOR..., 2017, on-line, tradução nossa).

No meu campo de ciências humanas, um artigo em coautoria seria classificado com menor valor do que um artigo em autoria única, para fins de promoção e posse. (SINGLE-AUTHOR..., 2017, online, tradução nossa).

Tenho sido repetidamente avisado que as pessoas mais novas (ou seja, aquelas que procuram o primeiro emprego para o TT (TenureTrack) e aquelas que vão continuar em breve devem ter pelo menos um artigo recente de autoria única, alegando que é impossível avaliar a contribuição de qualquer indivíduo para um trabalho de autoria múltipla. (SINGLE-AUTHOR..., 2017, on-line, tradução nossa).

Outras pessoas no meu departamento acham que o trabalho de um único autor mostra originalidade na pesquisa e responsabilidade para concluir um projeto sem assistência. (SINGLE-AUTHOR..., 2017, on-line, tradução nossa).

As declarações acima mostram que existem países, universidades e agências de fomento que dão mais valor à autoria única, pois se acredita que um pesquisador, para provar sua capacidade como cientista, deve publicar sozinho. A maior valorização estaria diretamente ligada ao fato de que a autoria única demonstra autonomia e capacidade científica, tornando o pesquisador apto a assumir determinados cargos e tarefas, como se fosse um "ritual de passagem". Além disso, o pesquisador que publica sozinho é visto como alguém que vai na contramão, que busca novidades, e isso parece ser valorizado pelos colegas cientistas.

"Eu faço isso simplesmente porque às vezes não consigo encontrar coautores confiáveis; ou coautores potenciais que são reconhecidos o suficiente no campo.” (NOOR, 2013, on-line, tradução nossa). Em outras palavras, esta declaração demonstra que, se não existe ainda um pesquisador reconhecido para trabalhar junto, há preferência pela autoria única. Não por acaso, que tal respondente continua: 
Além disso, honestamente falando, a discussão não nega a existência de um desejo natural de ganhar todo o crédito por si mesmo, especialmente quando você se encontra em potencial! (NOOR, 2013, on-line, tradução nossa).

Tal manifestação vai diretamente ao encontro do que foi trazido pela literatura antes, quando se aventou a ideia de que o pesquisador quer mesmo é o seu próprio reconhecimento.

Além disso, algumas obras podem ser inerentemente tarefas de um único autor, especialmente aquelas que lidam com o desenvolvimento de uma ideia. (NOOR, 2013, on-line, tradução nossa).

Meu campo não tem nenhum estigma contra autoria única (que eu conheço), então eu gosto de escrever trabalhos de autoria única para relatar teorias. Quando estes acabam sendo de alto impacto, pode ser especialmente benéfico para a redação de propostas como PI (Principal Investigator). (SINGLE-AUTHOR..., 2017, on-line, tradução nossa).

Trabalhos de autor único em física experimental e engenharia são hoje em dia, na maioria das vezes, revisões. Papéis teóricos ou de modelo de computador são outra coisa, nesses campos é mais fácil ter um único autor. (NOOR, 2013, on-line, tradução nossa).

Nesse mesmo sentido, outras declarações foram: "Uma vantagem do autor único, pelo menos nas Ciências Sociais, é adicionar ideias livres." (NOOR, 2013, on-line, tradução nossa); e "Nos centros de pesquisa ainda há pessoas que trabalham sozinhas." (NOOR, 2013, on-line, tradução nossa). Tais declarações mostram que a autoria única pode ser simplesmente um momento próprio de um pesquisador, em que ele necessita de espaço para refletir, para expandir seus pensamentos, ou mesmo, para escrever trabalhos teóricos.

No entanto, na minha opinião, os trabalhos de autoria única hoje em dia parecem ser feitos por pesquisadores que conseguiram muito em seu campo, para alcançar resultados específicos, novos e curtos que sejam adequados para publicação em artigos de autoria única. (ELIYAN, 2014, on-line, tradução nossa).

Se você está publicando em um tópico muito especializado, é mais provável que não haja coautores. Isso não significa que você é um 
herói solitário... Outra razão para a autoria única é talvez que você não é um autor convencional. (ELIYAN, 2014, on-line, tradução nossa).

Nessa linha de pensamento, houve mais uma declaração: "Os autores individuais podem ter ideias inovadoras que desafiam as crenças aceitas - tenho certeza de que isso é verdade.” (ELIYAN, 2014, on-line, tradução nossa). Estas manifestações demonstram o respeito e a admiração que os pesquisadores possuem pelo autor único. Há um consenso de que a autoria única não é uma tarefa fácil. Além disso, existem declarações que apontam para o fato de que o autor único pode ser um cientista revolucionário.

"Eu tenho o hábito de escrever como um único autor. Bem, eu não sabia que isso é algo importante!" (ELIYAN, 2014, on-line, tradução nossa). Este depoimento mostra que nem sempre a autoria única é um ato consciente do pesquisador. A autoria única pode simplesmente ser uma preferência de modo de trabalhar.

“Autoria única mostra independência ou isolamento?" (SINGLEAUTHOR..., 2017, on-line, tradução nossa). Esta manifestação em forma de pergunta coloca em xeque a autoria única. Seria ela uma maneira do pesquisador demonstrar toda a sua maturidade científica, mostrando que não precisa de alguém (presumindo que a sua autoria única não teve colaboração na pesquisa) ou seria a autoria única resultado da solidão - pessoal, geográfica, científica etc. - do pesquisador? Pode ser que a autoria única não tenha sua razão em nenhuma dessas duas suposições, podendo estar simplesmente ligada às características da área científica.

\section{Considerações finais}

Ainda que em proporções menores, a autoria única continua presente nas publicações científicas. Se em épocas passadas ela era regra, hoje ela é mínima. No entanto, a ideia que fica sugerida deste artigo, é que a autoria única não desaparecerá. 


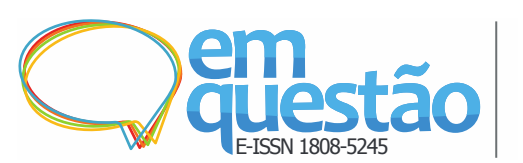

Os prováveis motivos para a sua continuidade no meio científico são muitos. Assim, preferência, área de pesquisa única, menor tempo de produção de artigos, pressão de instituições/nações, demonstração de competência, entre outras razões, fazem com que a autoria única ainda se faça presente no modo de produzir ciência pelos pesquisadores. Da mesma forma, o considerável respeito da comunidade científica pela autoria única, em que o pesquisador é percebido como alguém capaz e bem-sucedido, proporciona a continuidade das publicações científicas em autoria única. Além disso, a busca pelo reconhecimento científico (consagração pessoal) talvez seja a principal razão da continuidade da autoria única nas publicações científicas.

Interessante observar que, se na fase inicial desta pesquisa chegou-se a pensar que a autoria única fosse um tema já pacificado dentro da ciência, tal pensamento veio por terra durante o processo mais profundo de investigação. A ideia era a de revisar pontos da literatura a respeito do assunto que servissem de fundamento à pesquisa futura sobre os motivos que levam os pesquisadores a continuar escrevendo sozinhos. Não se cogitou que a autoria única fosse ainda assunto polêmico dentro da ciência, tampouco que fosse mais valorizada do que a coautoria dentro de algumas áreas de pesquisa, de determinadas instituições, e por outros pesquisadores. Tal achado foi extremamente motivador. Diante disso, é importante que os estudos a respeito da autoria única tenham prosseguimento, a fim de que se compreenda a continuidade desse fenômeno dentro da ciência. Desse modo, será possível não somente uma implementação adequada de políticas científicas, mas também será possível a obtenção de maior conhecimento a respeito da maneira de como a ciência é produzida.

Ademais, ainda que a proposta deste artigo visasse à autoria única, foi inevitável que a autoria múltipla ou coautoria viesse à tona. Assim sendo, algumas questões foram aventadas a respeito da coautoria. Seria ela uma evolução da ciência, ou ela é direcionada, quando na obrigação de dar coautoria ou quando na concorrência por financiamento de pesquisa. Se esses motivos são reais, caso não existissem, a pergunta que fica é se a autoria única ainda não seria preferência no modo de produzir ciência pelos pesquisadores, ao menos em 


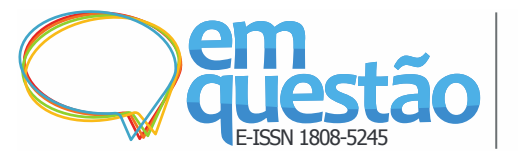

A autoria única nas publicações científicas: uma revisão de literatura

Daniela Gralha de Caneda Queiroz e Jayme Leiro Vilan Filho

determinadas áreas.

\section{Financiamento}

Agradecimento à Coordenação de Aperfeiçoamento de Pessoal de Nível Superior (CAPES).

\section{Referências}

ABT, Helmut. The Future of Single-Authored Papers. Scientometrics, Budapest, v. 73, n. 3, p. 353-358, Nov. 2007.

ARGENTINA. Comisión Interinstitucional de Elaboración de Criterios de Evaluación para las Humanidades y Ciencias Sociales. Centro de Estudios e Investigaciones Laborales - CONICET. Criterios de Evaluación de la Producción Científica de las Humanidades y Ciencias Sociales. Buenos Aires, 2012.

BEAVER, Donal; ROSEN, Richard. Studies in Scientific Collaboration: part I. The Professional Origins of Scientific Co-Authorship. Scientometrics, Dordrecht, v. 1, n. 1, p. 65-84, Sep. 1978.

BOURDIEU, Pierre. O Campo Científico. In: ORTIZ, Renato (org.). Pierre Bourdieu: sociologia. São Paulo: Ática, 1983. p. 122-155.

BOURDIEU, Pierre. Os Usos Sociais da Ciência: por uma sociologia clínica do campo científico. São Paulo: UNESP, 2004a.

BOURDIEU, Pierre. Para uma Sociologia da Ciência. Lisboa: Edições 70, 2004b.

CANCHUMANI, Roberto; LETA, Jacqueline. Colaboração e produtividade científica: a propósito do vínculo institucional do autor. In: ENCONTRO NACIONAL DE PESQUISA EM CIÊNCIA DA INFORMAÇÃO, 18., 2017, Marília. Anais [...] Marília: UNESP, 2017. p. 1-15.

CHANG, Chen-chi. The of value knowledge created by individual scientists and research groups. Journal of Scholarly Publishing, Toronto, v. 39, n. 3, p. 274293, Apr. 2008.

CHARTIER, Roger. A mão do autor e a mente do editor. São Paulo: UNESP, 2014.

CHINCHILLA-RODRÍGUEZ, Zaida; MIGUEL, Sandra; MOYA-ANEGÓN, Félix de. What factors affect the visibility of argentinean publications in humanities and social sciences in scopus? Some evidence beyond the 


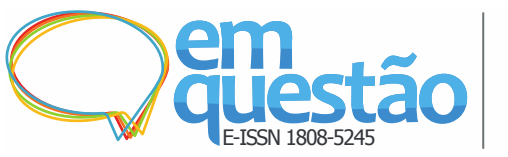

A autoria única nas publicações científicas: uma revisão de literatura

Daniela Gralha de Caneda Queiroz e Jayme Leiro Vilan Filho

geographic realm of research. Scientometrics, Budapest, v. 102, n. 1, p. 789810, Ago. 2014.

CHUANG, Kun-yang; HO, Yuh-shan. Bibliometric profile of top-cited singleauthor articles in the science citation index expanded. Journal of Informetrics, Amsterdam, v. 8, n. 4, p. 951-962, Oct. 2014.

COELHO, Gabriel. Sociologia do conhecimento e da ciência: da sua emergência a Pierre Bourdieu. Sinais, Vitória, v. 21, n. 2, p. 266-294, jul. 2017.

ELIYAN, Faysal (org.). Why is it becoming increasingly rare to see singleauthored journal papers? 10 Oct. 2014. Fórum iniciado por Faysal F. Eliyan, com 44 respostas. Disponível em: https://bit.ly/2Ylaktx. Acesso em: 27 mar. 2018.

FARBER, Miriam. Single-authored publications in the sciences at Israeli universities. Journal of Information Science, London, v. 31, n. 1, p. 62-66, Feb. 2005.

GREENE, Mott. The demise of the lone author. Nature, New York, v. 450, n. 7173, p. 1165, 2007.

HART, Richard. Collaboration and article quality in the literature of academic librarianship. The Journal of Academic Librarianship, Amsterdam, v. 33, n. 2, p. 190-195, Mar. 2007.

HARTLEY, James. Refereeing and the single author. Journal of Information Science, London, v. 31, n. 3, p. 251-256, Jun. 2005.

HARTLEY, James; CABANAC, Guillaume. Are two authors better than one? can writing in pairs affect the readability of academic blogs?. Scientometrics, Hoboken, v. 109, n. 3, p. 2119-2122, Sep. 2016.

HOCHMAN, Gilberto. A Ciência entre a comunidade e o mercado: leituras de Kuhn, Bourdieu, Latour e Knorr-Cetina. In: PORTOCARRERA, Vera (org.).

Filosofia, História e Sociologia das Ciências: abordagens contemporâneas. Rio de Janeiro: FIOCRUZ, 1994. Cap. 8.

KATZ, Sylvan; MARTIN, Ben. What is Research Collaboration? Research Policy, Amsterdam, v. 26, n. 1, p. 1-18, Mar. 1997.

KING, Christopher. Single-Author Papers: a waning share of output, but still providing the tools for progress. 2013. Disponível em:

http://sciencewatch.com/articles/single-author-papers-waning-share-output-stillproviding-tools-progress. Acesso em: 05 abr. 2016.

KUHN, Thomas. A Estrutura das Revoluções Científicas. 5. ed. São Paulo: Perspectiva, 1998. 
LARIVIÈRE, Vincent. On the Shoulders of Students? the contribution of PHD students to the advancement of knowledge. Scientometrics, Budapest, v. 90, n. 2, p. 463-481, Feb. 2012.

LE COADIC, Yves-François. A Ciência da Informação. 2. ed. Brasília: Briquet de Lemos, 2004.

LUUKKONEN, Terttu; PERSSON, Olle; SIVERTSEN, Gunnar. Understanding Patterns of International Scientific Collaboration. Science, Technology \& Human Values, Thousand Oaks, v. 17, n .1, p. 101-126, Jan. 1992.

MASLOW, Abraham. Maslow no gerenciamento. Rio de Janeiro: Qualitymark, 2001.

MEADOWS, Arthur. A comunicação científica. Brasília: Briquet de Lemos, 1999.

MERTON, Robert. O Efeito Mateus na Ciência II: a vantagem cumulativa e o simbolismo da propriedade intelectual. In: MARCOVICH, Anne; SHINN, Terry (Org.). Ensaios de Sociologia na Ciência. São Paulo: Editora 34, 2013. Cap. 8.

MERTON, Robert. Priorities in Scientific Discovery: a chapter in the sociology of science. American Sociological Review, Thousand Oaks, v. 22, n. 6, p. 635659, Dec. 1957.

MERTON, Robert. Social Theory and Social Structure. New York: The Free Press, 1968.

MEZA, Paulina; SABAJ, Omar; MATSUDA, Ken. La Autoría Única en SciELO Chile: prácticas autoriales en las áreas de la ciencia. Biblios: Journal of Librarianship and Information Science, Pittsburg, n. 66, p. 11-19, Jul. 2017.

NOBEL MEDIA AB (Suécia). Nobel Group Interests AB. Angus Deaton Facts. [2015]. Disponível em:

https://www.nobelprize.org/nobel_prizes/economic-

sciences/laureates/2015/deaton-facts.html. Acesso em: 2 maio 2018.

NOBEL MEDIA AB (Suécia). Nobel Group Interests AB. Edmund S. Phelps Facts. [2006b]. Disponível em:

https://www.nobelprize.org/nobel_prizes/economic-

sciences/laureates/2006/phelps-facts.html. Acesso em: 02 maio 2018.

NOBEL MEDIA AB (Suécia). Nobel Group Interests AB. Gerhard Ertl Facts. [2007]. Disponível em: https://www.nobelprize.org/nobel_prizes/chemistry/laureates/2007/ertlfacts.html. Acesso em: 2 maio 2018. 
NOBEL MEDIA AB (Suécia). Nobel Group Interests AB. Paul Krugman Facts. [2008]. Disponível em:

https://www.nobelprize.org/nobel_prizes/economicsciences/laureates/2008/krugman-facts.html. Acesso em: 02 maio 2018.

NOBEL MEDIA AB (Suécia). Nobel Group Interests AB. Roger D. Kornberg - Facts. [2006a]. Disponível em:

https://www.nobelprize.org/nobel_prizes/chemistry/laureates/2006/kornbergfacts.html. Acesso em: 2 maio 2018.

NOOR, Muhamad (org.). What is your opinion on single author papers? 2013. Fórum iniciado por M. M. Noor, com 24 respostas.

PRICE, Derek. Little Science, Big Science. New York: Columbia University, 1963.

REIF, Fred. The Competitive World of the Pure Scientist: the quest for prestige can cause conflict between the goals of science and the goals of the scientist. Science, Washington, v. 134, n. 3494, p. 1957-1962, Dec. 1961.

SINGLE-AUTHOR papers: a good or bad sign? 2017. Chronicle Forums, do jornal The Chronicle of Higher Education, de Washington. Disponível em: http://archive.fo/VB7Ia. Acesso em: 29 mar. 2018.

VANZ, Samile; STUMPF, Ida. Colaboração científica: revisão teóricoconceitual. Perspectivas em Ciência da Informação, Belo Horizonte, v. 15, n. 2, p. 42-55, maio 2010.

ZIMAN, John. An introduction to science studies: the philosophical and social aspects of science and technology. Cambridge: Cambridge University Press, 1988.

\title{
Single authorship in scientific publications: a literature review
}

\begin{abstract}
This article addresses the single authorship in scientific publications. It uses literature review as research methodology with three different approaches: single authorship itself, with historical facts and other arguments defending its continuity; the gains of single authorship to the author throughout its recognition by scientific community; and the status of single authorship, presenting works on this theme and some researchers' points of view. It ends stating that single authorship will remain, especially because it provides recognition.
\end{abstract}




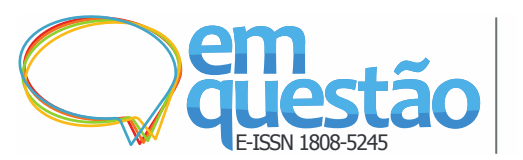

Keywords: Single authorship. Scientific publication. Recognition by scientific community. Literature review.

Recebido: 26/09/2018

Aceito: $11 / 12 / 2018$

${ }^{1}$ Nos dois primeiros segmentos, a revisão de literatura foi baseada em livros e artigos de periódicos das áreas de filosofia, sociologia, psicologia e história que tratassem do autor cientista. Já no terceiro segmento, as pesquisas relacionadas foram resultados de buscas em: Web of Science (WoS), Scopus, E-LIS repository, Library and Information Science Abstracts (LISA), Library, Information Science \& Technology Abstracts with Full Text (LISTA), Scientific Electronic Library Online (SciELO), Base de Dados de Periódicos em Ciência da Informação (BRAPCI), ABCDM, Google Scholar, Banco de Teses CAPES, Biblioteca Digital Brasileira de Teses e Dissertações (BDTD/IBICT), ResearchGate e The Chronicle of Higher Education. Para tanto, foram utilizados os termos: autoria única, autoria simples, single author, single authorship, simple authoring, solo writing e autoría única. As buscas foram realizadas entre janeiro e março de 2018.

${ }^{2}$ PONTILLE, David. La signature scientifique: une sociologie pragmatique de l'attribution. Paris: CNRS Éditions, 2004. Apud Larivière (2012).

${ }^{3}$ Disponível em: https://www.researchgate.net/. 